BNL -61136

Informal Report

\title{
A STUDY OF THE ELECTROCHEMICAL BEHAVIOR OF TUNGSTEN IN CAUSTIC SOLUTIONS AND PLATINUM/IRIDIUM IN CHLORIDE SOLUTIONS
}

\author{
Carissima M. Vitus and Hugh S. Isaacs \\ Materials Science Division \\ Brookhaven National Laboratory \\ Associated Universities, Inc. \\ Upton, Long Island, New York 11973 \\ and \\ Valeska Schroeder \\ College of Engineering \\ University of California, Berkeley \\ Berkeley, CA 94720
}

November 22, 1994

Under contract No. DE-AC02-76CH00016 with the

UNITED STATES DEPARTMENT OF ENERGY

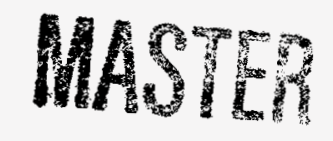




\section{DISCLAIMER}

This report was prepared as an account of work sponsored by an agency of the United States Government. Neither the United States Government nor any agency thereof, nor any of their employees, nor any of their contractors, subcontractors, or their employees, makes any warranty, express or implied, or assumes any legal liability or responsibility for the accuracy, completeness, or usefulness of any information, apparatus, product, or process disclosed, or represents that its use would not infringe privately owned rights. Reference herein to any specific commercial product, process, or service by trade name, trademark, manufacturer, or otherwise, does not necessarily constitute or imply its endorsement, recommendation, or favoring by the United States Government or any agency, contractor or subcontractor thereof. The views and opinions of authors expressed herein do not necessarily state or reflect those of the United States Government or any agency, contractor, or subcontractor thereof. 


\section{DISCLAIMER}

Portions of this document may be illegible in electronic image products. Images are produced from the best available original document. 


\section{Table of Contents}

Page No.

$\begin{array}{lc}\text { ABSTRACT } & 1 \\ \text { INTRODUCTION } & 2 \\ \text { EXPERIMENTAL } & 3 \\ \text { RESULTS AND DISCUSSION } & 6 \\ \text { The meniscus - Theory } & 6 \\ & 8\end{array}$

$\begin{array}{lr}\text { The meniscus - Aspect Ratio } & 8\end{array}$

$\begin{array}{ll}\text { Tungsten Electrochemistry } & 10\end{array}$

W Etching Experiments 13

$\begin{array}{lr}\text { Pt/Ir Etching Experiments } & 15\end{array}$

$\begin{array}{ll}\text { Light Emission Studies } & 17\end{array}$

$\begin{array}{ll}\text { The Etching Mechanism } & 20\end{array}$

$\begin{array}{ll}\text { Micromachining } & 20\end{array}$

CONCLUSIONS 23

ACKNOWLEDGEMENTS 23

$\begin{array}{ll}\text { REFERENCES } & 24\end{array}$

$\begin{array}{ll}\text { FIGURE CAPTIONS } & 26\end{array}$ 


\title{
A Study of the Electrochemical Etch Behavior of Tungsten in Caustic Solutions and Platinum/Iridium in Chloride Solutions
}

\author{
Carissima $M$. Vitus and Hugh $\mathbf{S}$. Isaacs \\ Department of Applied Science \\ Brookhaven National Laboratory \\ Upton, NY 11793 \\ and \\ Valeska Schroeder* \\ College of Engineering \\ University of California, Berkeley \\ Berkeley, CA 94720
}

\begin{abstract}
Platinum/iridium and tungsten wires were electrochemically etched in chloride and caustic solution, respectively, to produce tips with high aspect ratio. A direct relationship between the meniscus and the aspect ratio of etched tips was established. Scanning electron micrographs indicated that higher aspect ratios were obtained by changing the geometry of the meniscus during the etch either by an increase in the applied a.c. voltage or with the addition of a nonpolar layer above the electrolytic solution during the etching process. Above the breakdown voltage, two possible mechanisms appeared to control the etching process by expediting chemical dissolution: cavitation and sparking. Cavitation caused erosion due to the force of evolved gases against the electrode and sparking attacked the surface by vaporizing the metal. Sparking commenced on both wires near $25 \mathrm{~V}$. This voltage corresponded to a minimum in the plot of total etch time versus voltage. From light emission studies, sparking on $\mathrm{Pt} / \mathrm{Ir}$ was associated with the ionization of $\mathrm{Pt}, \mathrm{Ir}, \mathrm{Ca}$, and $\mathrm{Cl}$. A compositional analysis of insoluble black particles produced during a.c. and d.c. etching of $\mathrm{Pt} / \mathrm{Ir}$ revealed $\mathrm{Pt}$ and $\mathrm{Ir}$ as the major constituents of the product. The sparking process was shown to have a potential use in micromachining.

* Participant in Spring Semester Science and Engineering Program
\end{abstract}




\section{INTRODUCTION}

In the 1950's, field ion microscopy (FIM) was invented by Müller and was used to study the structure of clean metal surfaces as well as substrate-adsorbate interactions, surface defects and metal growth processes [1]. Higher resolution was achieved by preforming the metal surface into a sharp tapered cone by anodic polarization. Modifying electrochemical polishing methods developed by Tegart [2] and others [3-4] to polish thin metal foils, Müller etched metal rods in electrolytic solutions to form tip ends that were sharp, conical in shape and free of plastic deformation or work hardening. Similar methods are currently used to produce tips for use in techniques such as scanning tunneling microscopy (STM) and scanning vibrating probe (SVP) which require conical tips with an atomic radius of curvature to achieve maximum resolution.

The scanning vibrating probe maps current density distribution above a metal surface in an electrolytic environment. In operation, a platinum microelectrode is rastered across the surface using a piezoelectric bimorph. Two additional bimorphs allow the microelectrode to vibrate at different frequencies in two directions, orthogonal to the rastering direction. These frequencies interact with the ambient electric field to produce an a.c. signal due to changes in the local ionic current. Lock-in amplifiers detect the magnitude and sign of current vectors which correspond to anodic and cathodic sites on the surface. Sharp, high aspect ratio microelectrodes are needed in order to reduce solution convection caused by the vibrating microelectrode. A blunt microelectrode will have a more disruptive effect on the pattern of current flow above the surface than a sharp, tapered tip.

In STM, the topography of a conducting surface can be resolved to an atomic level by maintaining a constant current of electrons tunneling the gap junction $(<10 \AA)$ between the surface and a sharp, rastering tip [5-9]. The magnitude of the current is inversely. proportional to the gap distance. Thus, a $1 \AA$ increase in gap distance causes the current to increase by an order of magnitude. A blunt or jagged tip apex can drastically affect the tunneling current response to real surface topography which will result in an erroneous image. This relationship dictates that the resolution of the image is directly proportional to the geometric shape of the tip apex. It is generally accepted that a high quality tip is one that gradually tapers to an atomically fine point without surface roughness. With this in mind, the production of reproducible, high quality tips which can achieve atomic resolution is needed for STM.

Currently, no one method has been found to manufacture reproducible, high quality tips. Tips have been manufactured by a number of methods including ion milling [10], field emission [11-12], cutting with wire cutters [13], grinding [14] and electrochemical etching/polishing [6-9]. Of the methods reported in the literature, electrochemical etching 
using either a.c. or d.c. voltages has been the most commonly used. In this method, a narrow diameter wire, frequently platinum/iridium and tungsten for STM applications, is etched under applied potential in a solution specific to the tip material, causing dissolution of the wire to a fine point at the solution air interface.

Several refinements of the electrochemical method are found in the literature. Following a standard electrochemical etch of $\mathrm{W}$ in $1 \mathrm{M} \mathrm{NaOH}$, Fotino inverted the resulting tip and resumed the etching process. The inverted tip was sharpened at the apex by taking advantage of the upward bubble flow during the etch process [6]. Musselman and Russell stipulate an alternate polishing method for $\mathrm{Pt} / \mathrm{Ir}$ wire etched in $60 \%$ saturated $\mathrm{CaCl}_{2}, 36 \% \mathrm{H}_{2} \mathrm{O}$, and $4 \% \mathrm{HCl}$ by volume. After completion of an etch, the end of the tip was stepped through a counter electrode loop which contained solution. Using this method, a small cross section of the tip may be selectively polished to obtain the desired geometry [7]. Zhang and Wang etched a $\mathrm{Pt} / \mathrm{Ir}$ wire in $3 \mathrm{M} \mathrm{KCN}$ and $1 \mathrm{M} \mathrm{NaOH}$. The wire was coated with a nonpolar paraffin on the portion of the shaft immediately above and below the solution-air interface. This coating decreases the meniscus length, effectively shortening the aspect ratio of the tip, in order to limit vibrations of the tip in service [8]. Enhancement of the tip quality is reported in each case.

In this paper, the processes by which platinum/iridium in chloride solutions and tungsten in caustic solutions are electrochemically etched by applied a.c. and d.c. potentials will be examined. Current density profiles as a function of $\mathrm{pH}$ and voltage will be discussed for $W$ in caustic environments. The tip apex was analyzed by microscopic examination using scanning electron microscopy (SEM). The dependence of the aspect ratio on the meniscus will be demonstrated. Spectral analysis of thermionic emissions observed during sparking at high etching voltages will also be presented. Particles formed during the etch of $\mathrm{Pt} / \mathrm{Ir}$ were analyzed using energy dispersive spectroscopy (EDS). The potential for use of the sparking process as a micromachining technique will also be discussed.

\section{EXPERIMENTAL}

Platinum/iridium 80:20 and tungsten wire, 0.01 inch in dia., were obtained from F. H. C., Brunswick, ME. Platinum/iridium was etched in a 2:1 aqueous solution of $18 \mathrm{M} \Omega$ (Millipore Milli-Q) $\mathrm{H}_{2} \mathrm{O}: \mathrm{CaCl}_{2}$, sat. (Fischer; analytical reagent grade, $99.4 \%$ ). Tungsten was etched in aqueous solutions of $\mathrm{KOH}$ (J. T. Baker; reagent grade, 87.1\%) and $\mathrm{NaOH}$ (Mallinckrodt; analytical reagent grade, $98.2 \%$ ). Wires were immersed $2 \mathrm{~mm}$ below the solution/air interface at the start of each experiment. A Powerstat variable autotransformer (The Superior Power Co., Bristol, Connecticut) was used to etch under a. c. voltage conditions $(0-100 \mathrm{~V})$. A constant d. c. voltage $(0-180 \mathrm{~V})$ was supplied by 
a TCR Power Supply (300S2-1 Electronic Measurements Inc.). The experimental apparatus used to etch wires is depicted in Figure 1. The counter electrode in all experiments was a loop of platinum centered around the working electrode of $\mathrm{W}$ or $\mathrm{Pt} / \mathrm{Ir}$. A low density organic fluid (S.A.E. 30 weight, Mobil) was used to alter the meniscus of the tip present at the solution interface.

Current density profiles for tungsten in concentrations of $\mathrm{NaOH}$ in a $\mathrm{pH}$ range of 12.1 to 14.8 were acquired in a standard three electrode cell as shown in Figure 2. The electrochemical cell included an inlet port for solution (deaerated 20 minutes prior to each experiment) and ports for $\mathrm{N}_{2}$ gas (Liquid Carbonic). The counter electrode was a Pt wire and the reference electrode was $\mathrm{Hg} / \mathrm{Hg}_{2} \mathrm{SO}_{4}(+0.665 \mathrm{~V}$ vs. NHE). A 362 Scanning Potentiostat (EG\&G Princeton Applied Research) was used to control the applied potential. Prior to each experiment, the tungsten rod (0.3 inch dia.) was polished to 600 grit using $\mathrm{SiC}(3 \mathrm{M})$. Microshield lacquer (Pyramid Plastics Inc., Hope, Arkansas) was applied to insulate the sides of the rod so that solution only contacted the face of the rod. Prior to each experiment, tungsten was held at open circuit for 10 minutes. The dependence on solution convection was tested by attaching the wire in a stainless steel holder to an analytical rotator (Pine Instrument Co., Grove City, Pennsylvania). Tips were etched at rotation rates between 0 and $5000 \mathrm{rpm}$.

Photomicrographic images of etched tips were obtained using a JEOL JSM-6400 scanning electron microscope (SEM). The samples were affixed to a metal holder with carbon paint and then inserted into the vacuum chamber. An accelerating voltage of $25 \mathrm{keV}$ was used to acquire images. A magnification of $750 \mathrm{X}$ was used to estimate the aspect ratio which is presented in terms of the cone half angle. Photomicrographs presented herein were captured using Polaroid 553 film.

Particle size and composition of product formed during the $\mathrm{Pt} / \mathrm{Ir}$ etch was analyzed using a JEOL JSM-2000FX transmission electron microscope (TEM) equipped with a LINK light element energy dispersive spectroscopy (EDS) detector .

A video graphic printer (Sony, UP-850N) was used to capture frame by frame real time etching reactions that were recorded on a VHS video cassette recorder (Sony, SLV373UC) using a CCD-Iris color video camera (Sony, SSC-C374).

Spectral analysis of the light emitted during sparking at high voltages, both a.c. and d.c., was measured using a scanning monochromator (Jarrell-Ash) equipped with a single grating ( $300 \mathrm{~nm}$ blaze). The entrance and exit slits were $1 \mathrm{~mm}$ in width. Experiments of $\mathrm{W}$ in $\mathrm{NaOH}$ and $\mathrm{KOH}$ solutions and $\mathrm{Pt} / \mathrm{Ir}$ in $\mathrm{CaCl}_{2}, \mathrm{LiCl}$ and $\mathrm{KCl}$ solutions were conducted in a quartz crystal flat cell positioned directly in front of the entrance slit. The monochromator made successive scans from 250 to $650 \mathrm{~nm}$ in a $0.5 \mathrm{sec}$. sweep. 


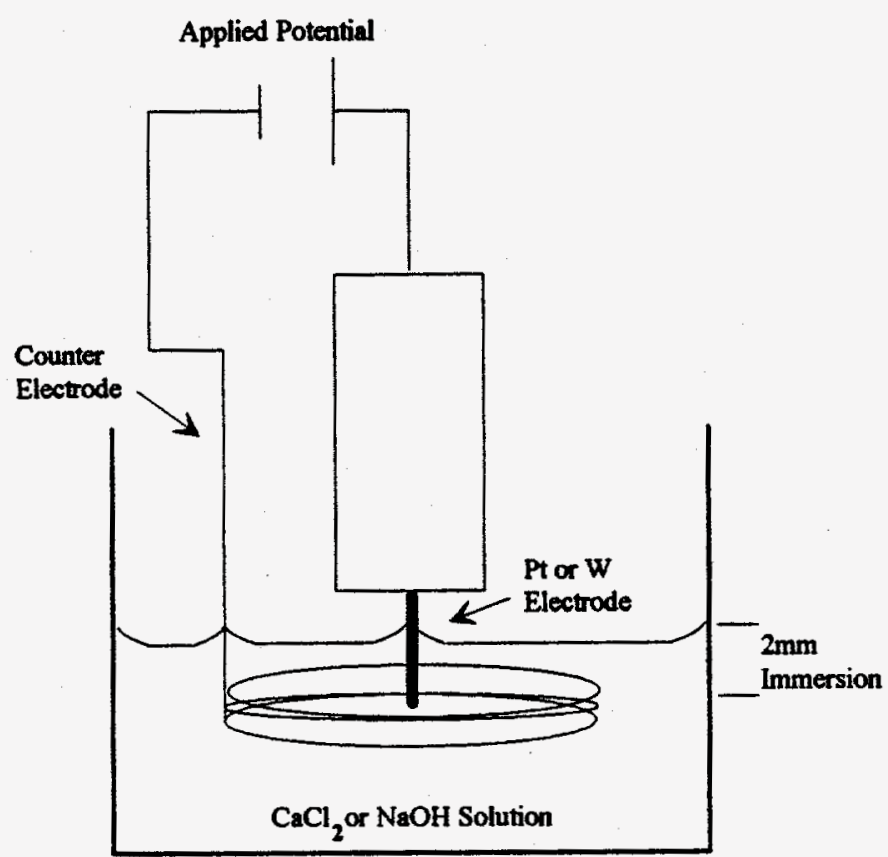

Figure 1. A sketch of the apparatus used to etch $\mathrm{W}$ and $\mathrm{Pt} / \mathrm{Ir}$ wires.

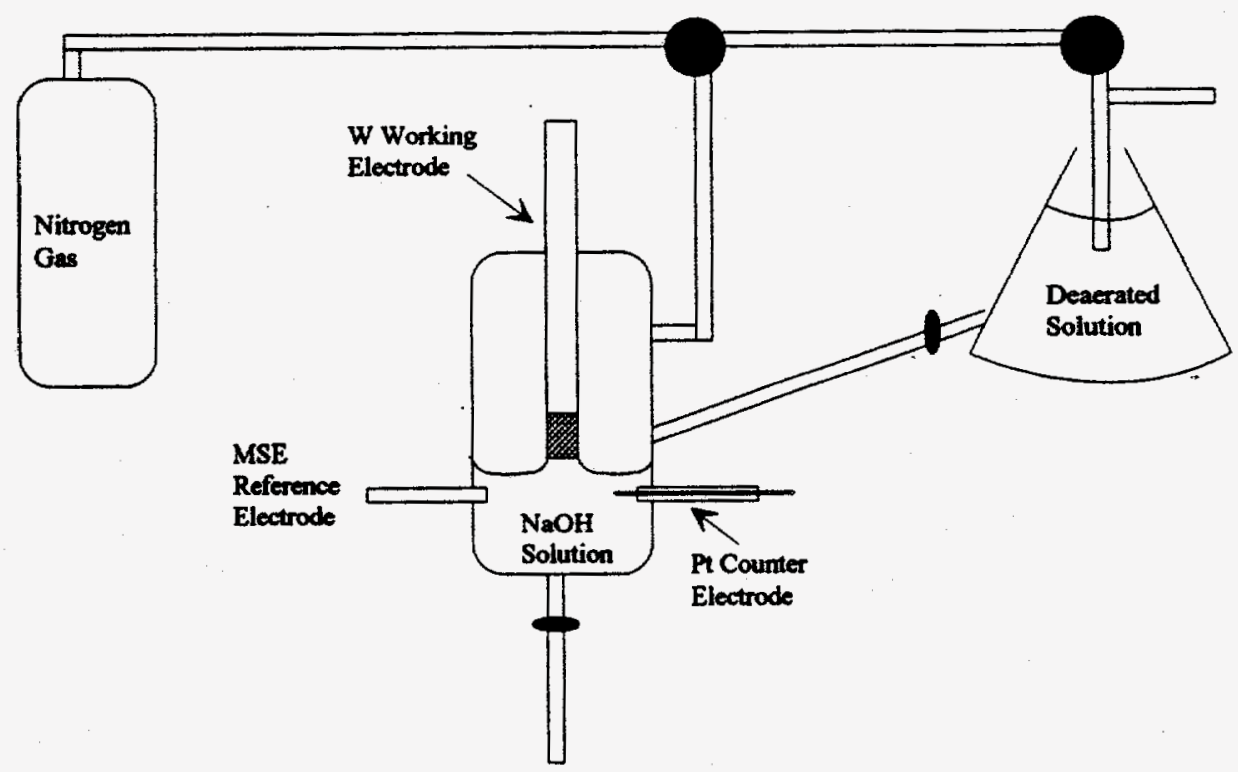

Figure 2. Diagram of electrochemical cell used to study voltammetric behavior of W in caustic solutions. 
Fluorescence line intensity versus wavelength spectra presented in this report are summations of 10 consecutive sweeps.

\section{RESULTS AND DISCUSSION}

The following general observations occur during the etching process of $\mathrm{Pt} / \mathrm{Ir}$ and $\mathrm{W}$ wires. In all cases, the meniscus on $\mathrm{W}$ was observed to be longer than that which forms on Pt/Ir. At potentials above the breakdown for each metal, aggressive gaseous evolution ensued during the reaction along the immersed shaft, disrupting the solution at the meniscus. As the reaction proceeded, the meniscus lowered on the shaft of the electrode revealing a polished surface, angled from the base of the shaft. The reaction terminated when the portion of the shaft in solution completely dissolved, with the tip ending in a fine point at the air-solution interface as shown in Figure 3. Further, light in the form of sparks or plasma was emitted from both wires during the course of the reaction when the applied voltage exceeded $30 \mathrm{~V}$ a.c. or $80 \mathrm{~V}$ d.c.

\section{The meniscus - Theory}

When etching a narrow diameter wire of $\mathrm{W}$ or $\mathrm{Pt} / \mathrm{Ir}$, the final geometry of the tip depended on the shape of the meniscus formed on the wire at the solution/air interface because only that portion of the shaft in solution can take part in the etching process. The contact angle between solution and wire has been determined by balancing forces of liquid-liquid cohesion and liquid-metal adhesion [15]. As the reaction proceeded, the meniscus lowers its position on the wire. Three proposed theories are put forth to explain this phenomena.

The first theory, modeled in Figure 4, assumes that etching occurs faster in the bulk solution due to the availability of reactant ions necessary to etch the metal. During the etching process, reactant ions are depleted, yielding a concentration gradient between the bulk solution and the top of the meniscus. Also, gaseous evolution causes bubbles to flow up the length of the shaft which continuously reduces the amount of solution in contact with the metal at the top of the meniscus. A combination of the two effects induces a conical shaped tip with the least amount of etch occurring at the top of the meniscus.

A second theory proposes that a balance of force on the solution, surface tension acting in the upward direction and gravity acting downward, is maintained throughout the etching process. Assuming the meniscus remained in its initial position after some portion of the wire was etched away, then more solution would be contained by the meniscus in the void made by the loss of metal. The additional weight of this solution would increase 


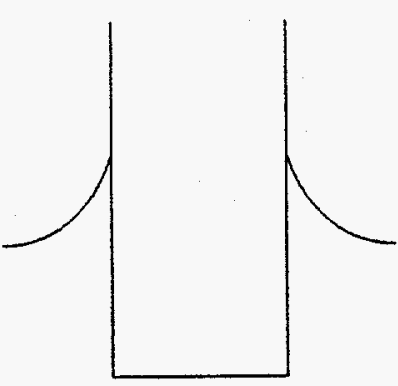

Prior to Etch

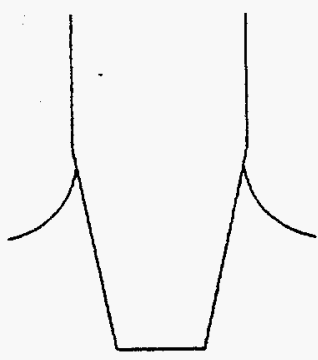

During Etch

Figure 3. Model of tip formation during an electrochemical etch.

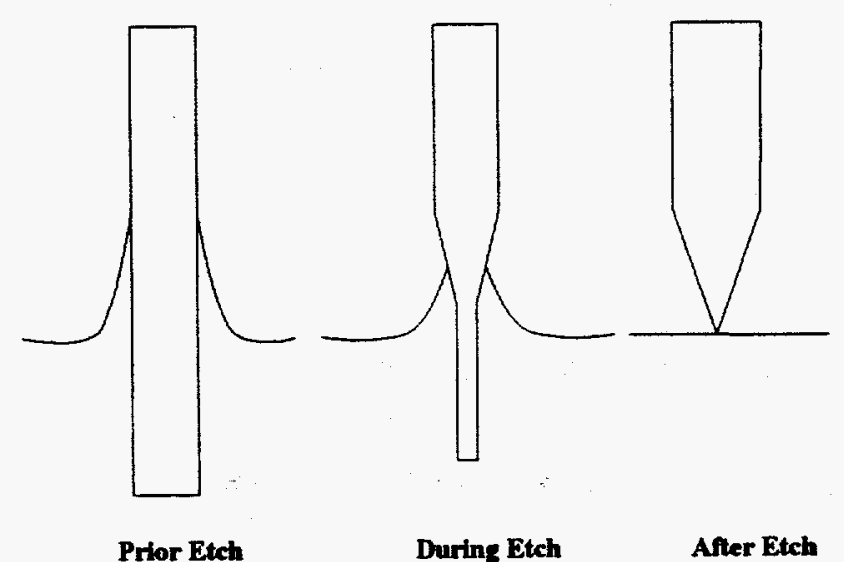

Figure 4. Model of meniscus shape at the air-solution interface before, during and after an electrochemical etch.

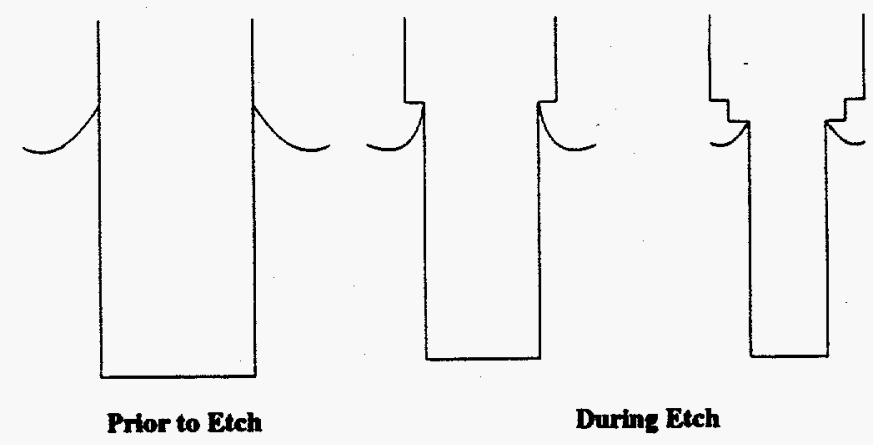

Figure 5. Model of meniscus shape as a function of shaft diameter at the air-solution interface during an electrochemical etch. 
the effective gravitational force. This force would change the overall balance of forces. To decrease the gravitational force, regaining a force balance, some of the solution weight would need to be removed from the meniscus. To lose solution weight, the meniscus must lower in proportionality with the amount of metal lost during the etch. Therefore, as metal is removed during the course of the etch, the meniscus must continue to lower until the etch terminates in a point at the solution/air interface. This corroborates experimental evidence.

A third theory is proposed assuming that the shaft etches uniformally in solution. During the etch, cylinders of incrementally decreasing diameter are formed as shown in the model in Figure 5. As the reaction progresses, the cylinder diameter decreases, affecting the gravitational forces on the meniscus and decreasing the area of the metalsolution interface, thus reducing the interfacial tension. These changes result in lowering the meniscus. Incremental steps continue throughout the reaction as the cylinder immersed in solution decreases. This theory is not supported by experimental evidence.

\section{The meniscus - Aspect Ratio}

When an a. c. voltage was applied to $\mathrm{W}$ wire in $1 \mathrm{M} \mathrm{NaOH}$, a vigorous reaction corresponding to aggressive hydrogen gas evolution below $-1.6 \mathrm{~V}$ MSE or oxygen evolution above the breakdown potential at $\approx 8.1 \mathrm{~V}$ MSE caused bubbling of the solution in the meniscus above the solution/air interface yielding a meniscus higher than that found during stagnant conditions. The height of the meniscus during the etch was found to be potential dependent between $5 \mathrm{~V}$ and $30 \mathrm{~V}$ a.c., with $30 \mathrm{~V}$ yielding the highest meniscus. The corresponding aspect ratio was found to be higher at the higher potentials and etching at $30 \mathrm{~V}$ a. c. reproducibly yielded the sharpest, tapered tip. This is demonstrated in Figures 6A and 6B, which show SEM photomicrographs of $W$ wire etched at 10 and $30 \mathrm{~V}$ a.c., respectively. The aspect ratio is expressed in terms of the cone half angle. Accordingly, an increase in the aspect ratio is synonymous with a decrease in cone half angle. Aspect ratios measured $12.2^{\circ}$ and $5.9^{\circ}$ for tips shown in Figures $6 \mathrm{~A}$ and $6 \mathrm{~B}$, respectively. Tips etched above $30 \mathrm{~V}$ a.c. yielded even higher aspect ratios, but in most cases, the formation of a rounded protrusion at the tip apex of high radius of curvature was observed. This is illustrated in the photomicrograph in Figure $6 \mathrm{C}$, where a rounded protrusion approximately 20 microns in diameter is observed. As a general rule, the sharpest reproducible tips are formed at roughly $30 \mathrm{~V}$ a.c.

The effect of the length of the meniscus on the aspect ratio was further investiated using polar-nonpolar phases. In this technique, a non-polar oil of lower density covered the etching solution. Gaseous evolution during the etching process forcefully drove the etching solution into the more viscous non-polar layer, trapping the etchant at the wire/nonpolar interface. This reproducibly yielded tips with higher aspect ratios. The 

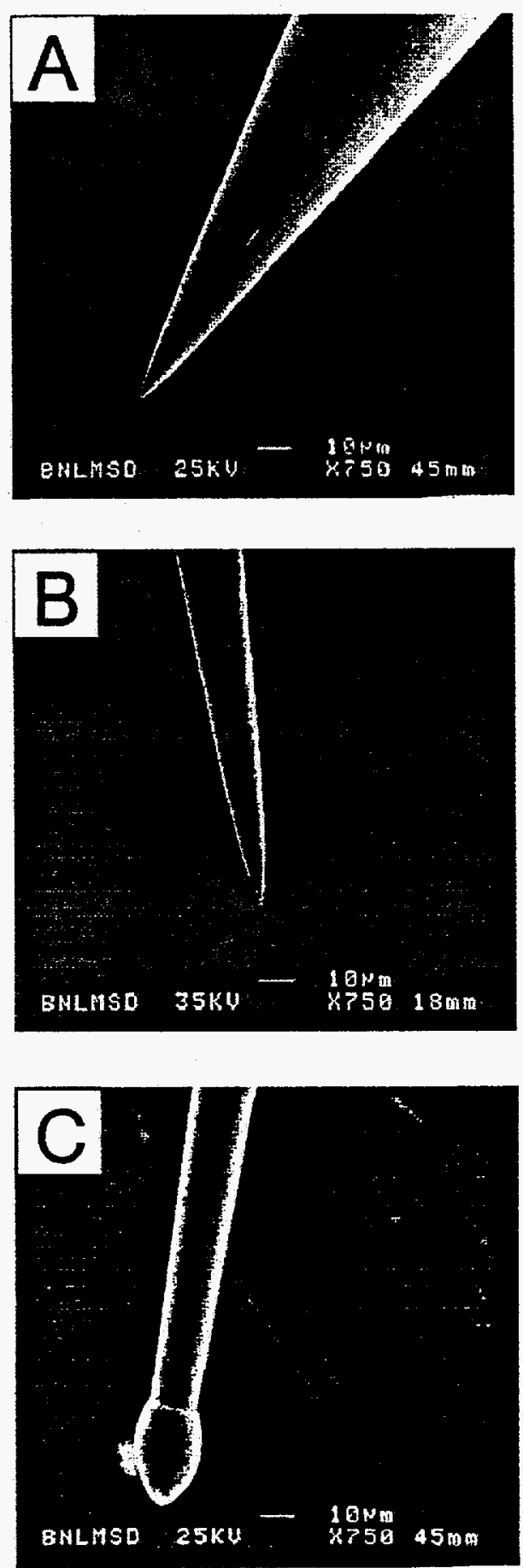

Figure 6. SEM micrographs of $\mathrm{W}$ etched in $1 \mathrm{M} \mathrm{NaOH}$ at A.) $10 \mathrm{~V}$ a.c. B.) $30 \mathrm{~V}$ a.c. and $\mathrm{C}$.) $50 \mathrm{~V}$ a.c.. 
technique was especially relevant for $\mathrm{Pt} / \mathrm{Ir}$ tips because $\mathrm{CaCl}_{2}$ is not a strong wetting agent and, in general, $\mathrm{Pt} / \mathrm{Ir}$ tips appeared blunt. To demonstrate this effect, a comparison of two $\mathrm{Pt} / \mathrm{Ir}$ tips etched in $\mathrm{CaCl}_{2}$ and in $\mathrm{CaCl}_{2}$ covered with a nonpolar phase are illustrated in Figure $7 \mathrm{~A}$ and $7 \mathrm{~B}$. The measured aspect ratio is $48.6^{\circ}$ for the tip etched in the absence of the nonpolar phase as shown Figure $7 \mathrm{~A}$ and is $11.3^{\circ}$ for the tip covered with the nonpolar phase, Figure 7B. From these results, it was concluded that etching with a nonpolar layer on top of the etchant solution has a significant influence on the overall tip shape producing high aspect tips.

\section{Tungsten Electrochemistry}

The current-voltage behavior of $\mathrm{W}$ in $\mathrm{NaOH}, \mathrm{pH} 12.1$, is shown in Figure 8. The first peak at $-0.27 \mathrm{~V}$ corresponds to the oxidation of $\mathrm{W}$ metal to the +3 state. The corresponding peaks at $+0.12 \mathrm{~V}$ and $+0.52 \mathrm{~V}$ are associated with further oxidation to the final state of +6 , forming $\mathrm{WO}_{3}$. Figure 9 illustrates the current-voltage behavior of $W$ at a $\mathrm{pH}$ of 14.0. In both $\mathrm{pH}$ solutions, the anodic current remained relatively constant at potentials above peak three. A significant increase in current density was obtained when the $\mathrm{pH}$ was increased. For $\mathrm{pH} 12.1$, the measured current density above peak 3 is 1.5 $\mathrm{mA} / \mathrm{cm}^{2}$ as compared to $240 \mathrm{~mA} / \mathrm{cm}^{2}$ measured at a $\mathrm{pH} 14.0$. This current-density behavior observed as a function of $\mathrm{pH}$ is similar to those reported in the literature [16-18].

Tungsten in a caustic environment dissolves anodically by passing through a number of valence states, resulting in the soluble $\mathrm{WO}_{4}^{-2}$ phase [16-18]. The currentvoltage behavior has been studied in $\mathrm{NaOH}$ solutions in a $\mathrm{pH}$ range of 7-13 by Ortiz and coworkers [16]. Their results also showed three current maxima in the voltammogram at $0 \mathrm{~V},+0.5 \mathrm{~V}$, and $+0.8 \mathrm{~V}$ versus SHE. They determined that the first peak was controlled by mass transport of $\mathrm{OH}^{-}$ions in a chemical dissolution process. The remaining peaks corresponded to an increase in oxidation state of $\mathrm{W}$, terminating in the +6 state, $\mathrm{WO}_{3}$. Above $+0.8 \mathrm{~V}$, tungsten oxide continued to form on the electrode. This oxide is then chemically converted to a soluble $\mathrm{WO}_{4}^{-2}$ species in the presence of $\mathrm{OH}^{-}$, leading to dissolution of the oxide.

The current-voltage behavior of $\mathrm{W}$ in caustic solutions was expanded by Johnson and coworkers. In their results, an increase in current density was observed up to the potential $+0.8 \mathrm{~V}$ vs. SHE. At higher potentials, the current density remains approximately constant until $28 \mathrm{~V}$, at which point, the current density augments to $70 \mathrm{~V}$ [17]. Kelsey conducted experiments at low potentials but significantly higher $\mathrm{pH}, 13.90-15.09$. In his report, a plot of $\log \mathrm{i}\left(\mathrm{A} / \mathrm{cm}^{2}\right)$ vs. $\log \mathrm{OH}^{-}$activity yielded a slope of +1 , indicative of a first-order rate dependence on $\mathrm{OH}^{-}$activity. This dependence was observed in results presented in this paper. The following reaction scheme was presented to explain the electrochemical process of $\mathrm{W}$ dissolution [18]. 

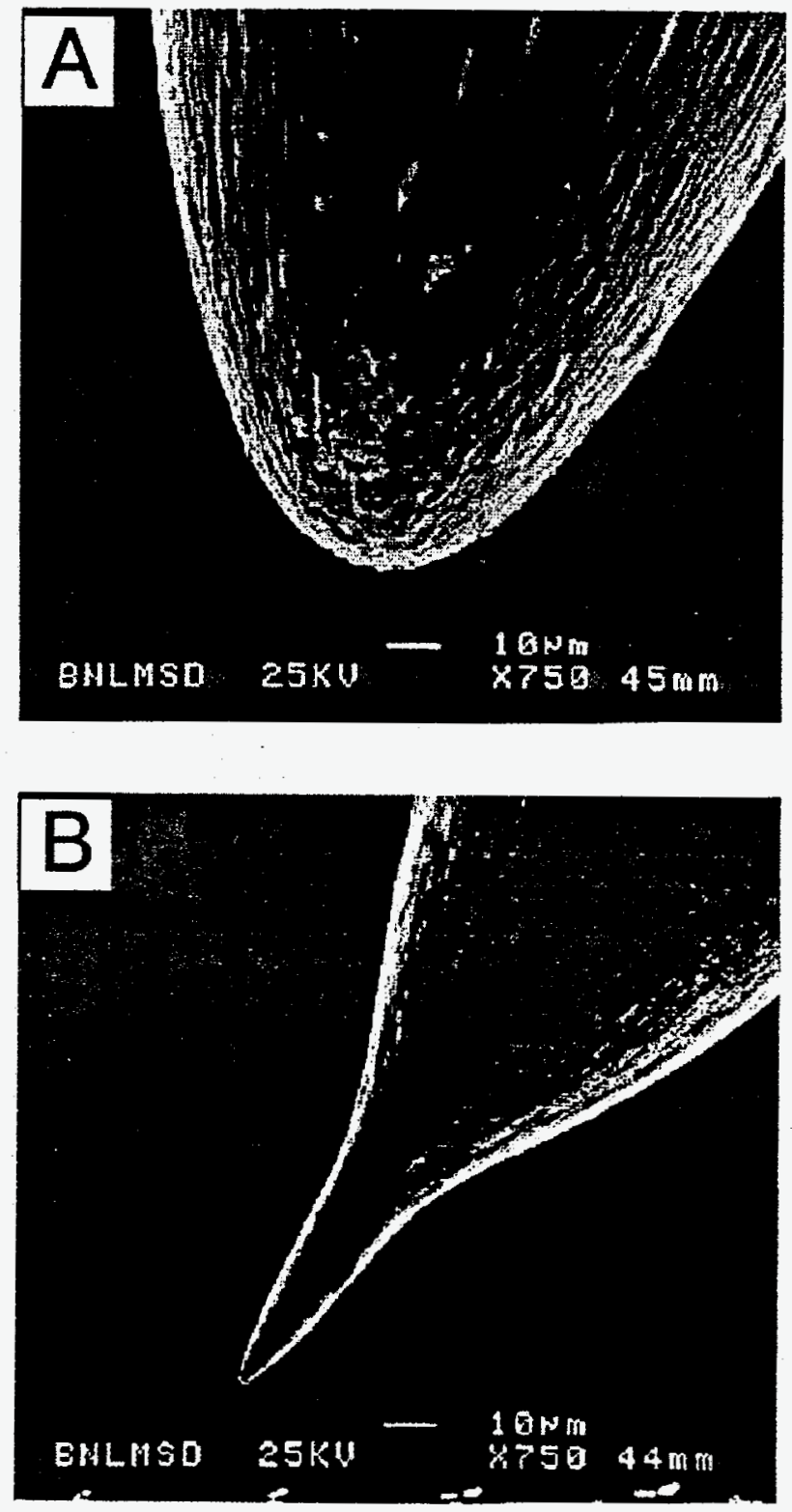

Figure 7. SEM micrographs of $\mathrm{Pt} / \mathrm{Ir}$ wire etched in $2: 1 \mathrm{H}_{2} \mathrm{O}: \mathrm{CaCl}_{2}$ at $20 \mathrm{~V}$ a.c. A.) without a nonpolar overlayer and B.) with a nonpolar overlayer of oil on top of the solution. 


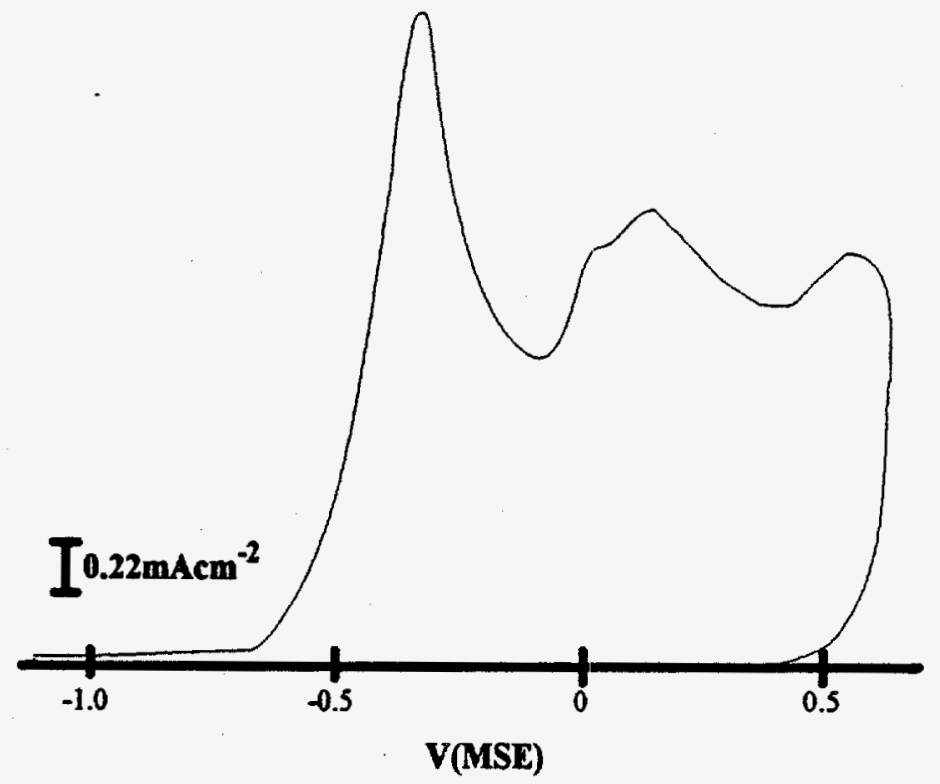

Figure 8. A current-voltage plot of $\mathrm{W}$ rod in $0.0125 \mathrm{M} \mathrm{NaOH}$ with a total ion activity of $1 \mathrm{M}$ by the addition of $\mathrm{Na}_{2} \mathrm{SO}_{4}$. Scan rate: $0.1 \mathrm{~V} / \mathrm{sec}$.

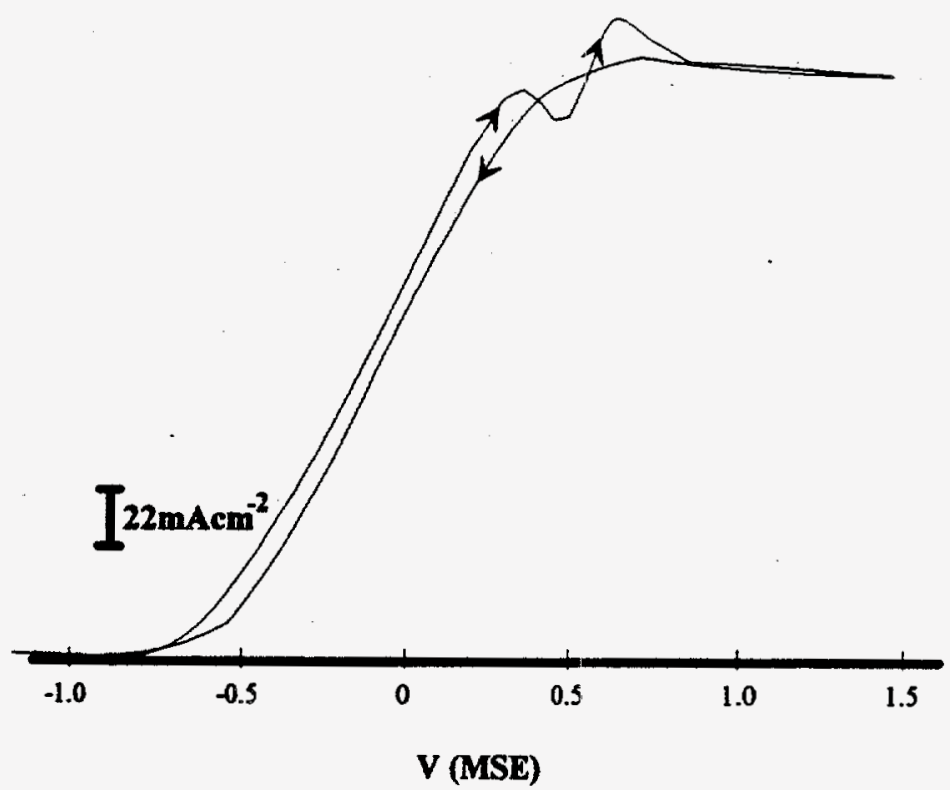

Figure 9. A current-voltage plot of $\mathrm{W}$ rod in $1 \mathrm{M} \mathrm{NaOH}$. Scan rate: $0.1 \mathrm{~V} / \mathrm{sec}$. 


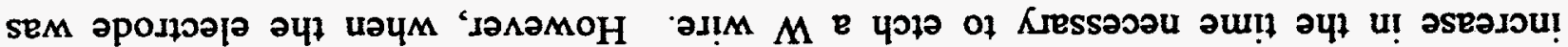

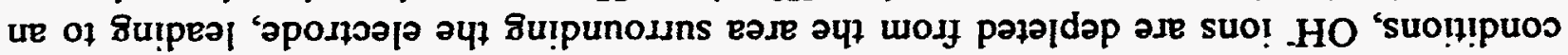

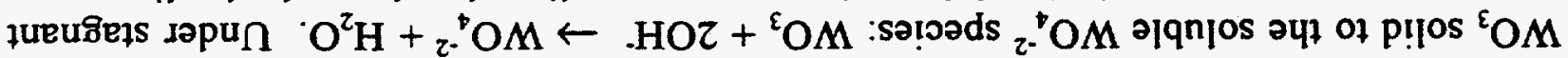

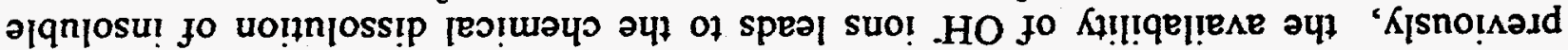

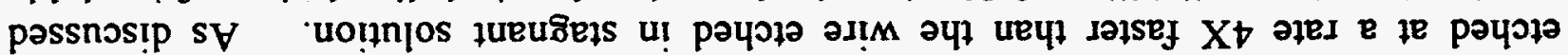

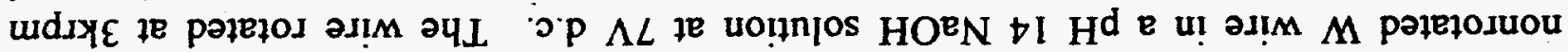

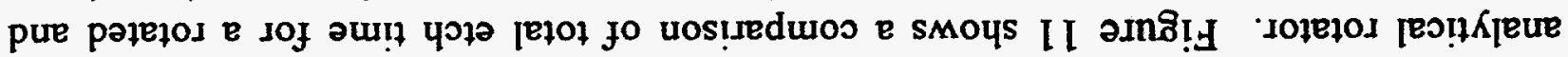

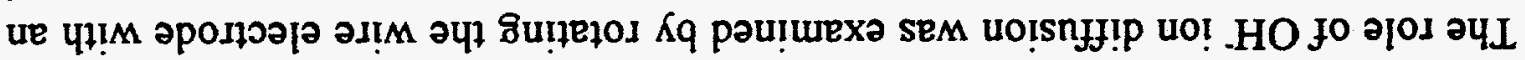

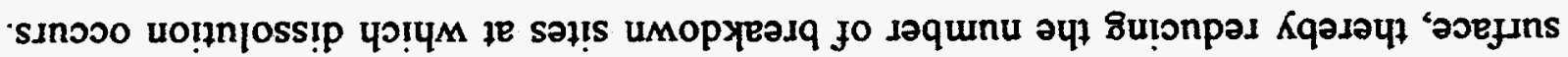

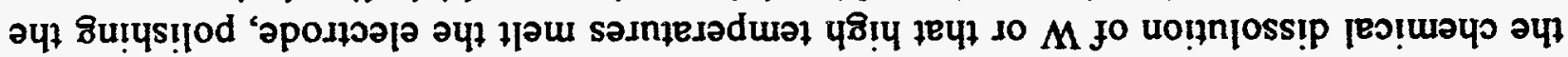

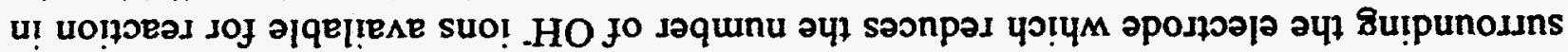

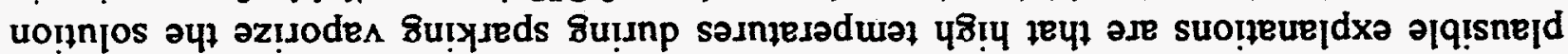

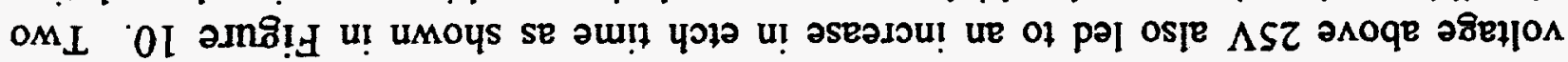

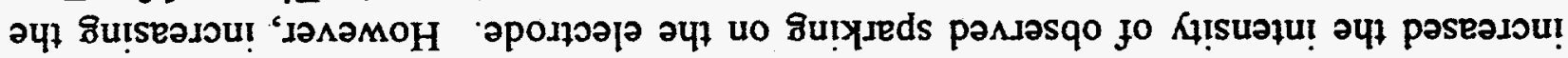

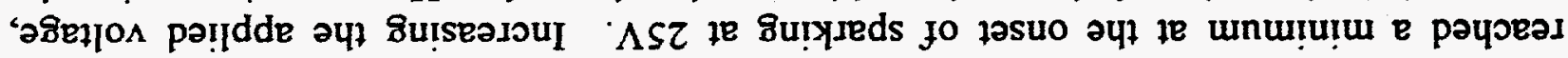

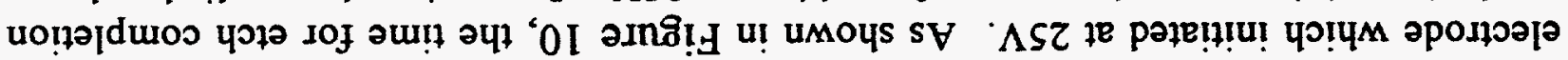

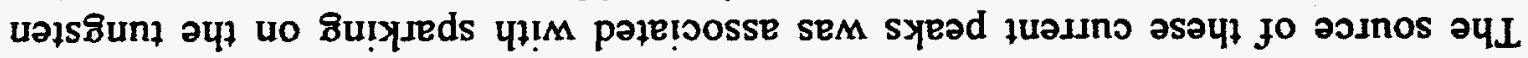

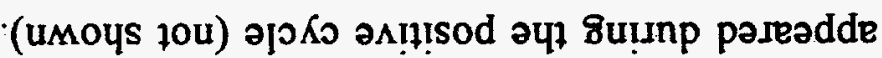

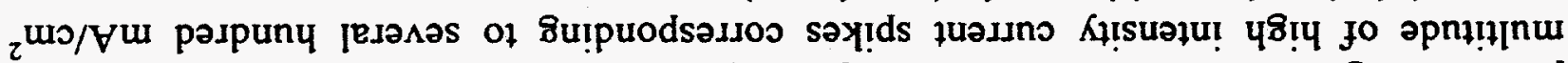

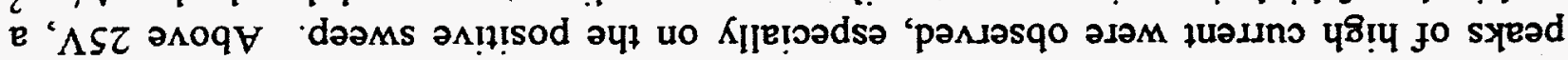

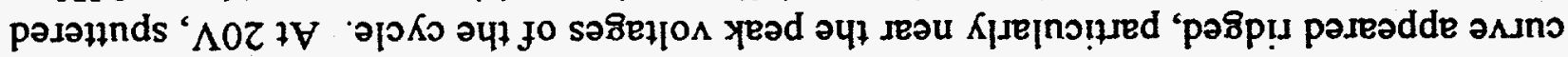

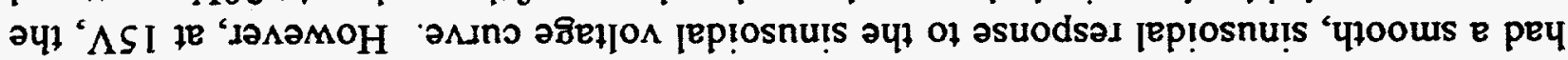

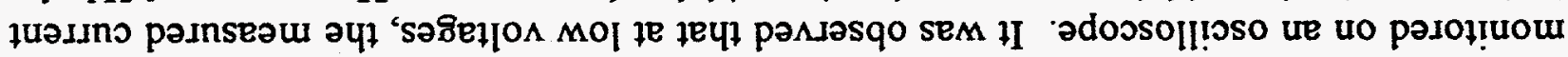

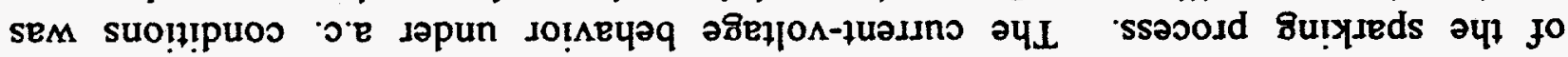

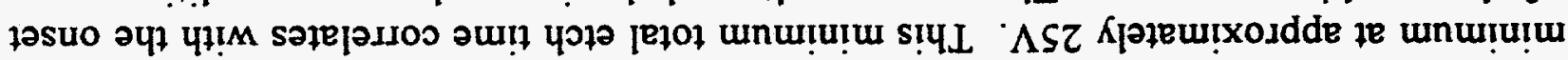

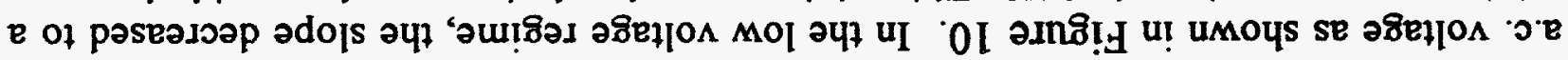

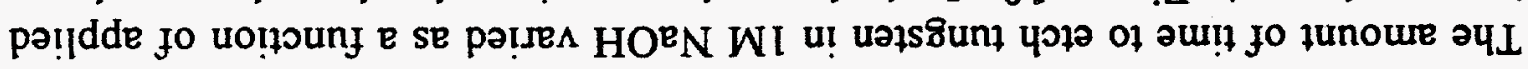

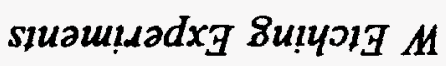

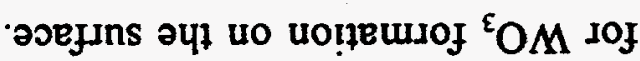

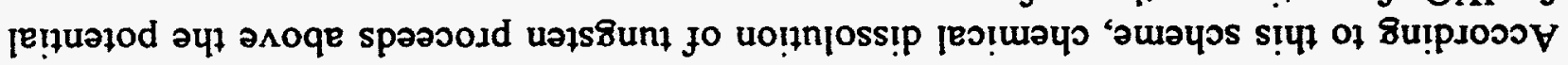

$$
\begin{aligned}
& \mathrm{O}^{2} \mathrm{H}+{ }_{(\mathrm{bes})}^{(\mathrm{O}) \mathrm{OM}} \leftarrow \mathrm{HO}+{ }^{(b \mathrm{t})} \div \mathrm{OMH} \\
& \text { (be) }{ }^{\circ} \mathrm{OMH} \leftarrow . \mathrm{HO}+{ }^{(\mathrm{s})} \mathrm{OM} \\
& -a+{ }^{\left({ }^{(8)} \mathrm{O}\right.} \mathrm{OM} \leftarrow \mathrm{HO}+{ }^{(\mathrm{s})} \mathrm{H}^{\varepsilon} \mathrm{OM} \\
& -a+{ }^{(s)} \mathrm{H}^{\varepsilon} \mathrm{OM} \leftarrow . \mathrm{HO}+{ }^{(2)} \mathrm{OM} \\
& \mathrm{O}^{z} \mathrm{H}+-a+{ }^{(v) \tau} \mathrm{OM} \leftarrow . \mathrm{HO} z+{ }^{(8)}+\mathrm{OM} \\
& \mathrm{O}^{2} \mathrm{H}+-\partial \mathcal{- a}+{ }^{(s)} \mathrm{OM} \leftarrow . \mathrm{HOZ}+{ }^{(8)} \mathrm{M}
\end{aligned}
$$




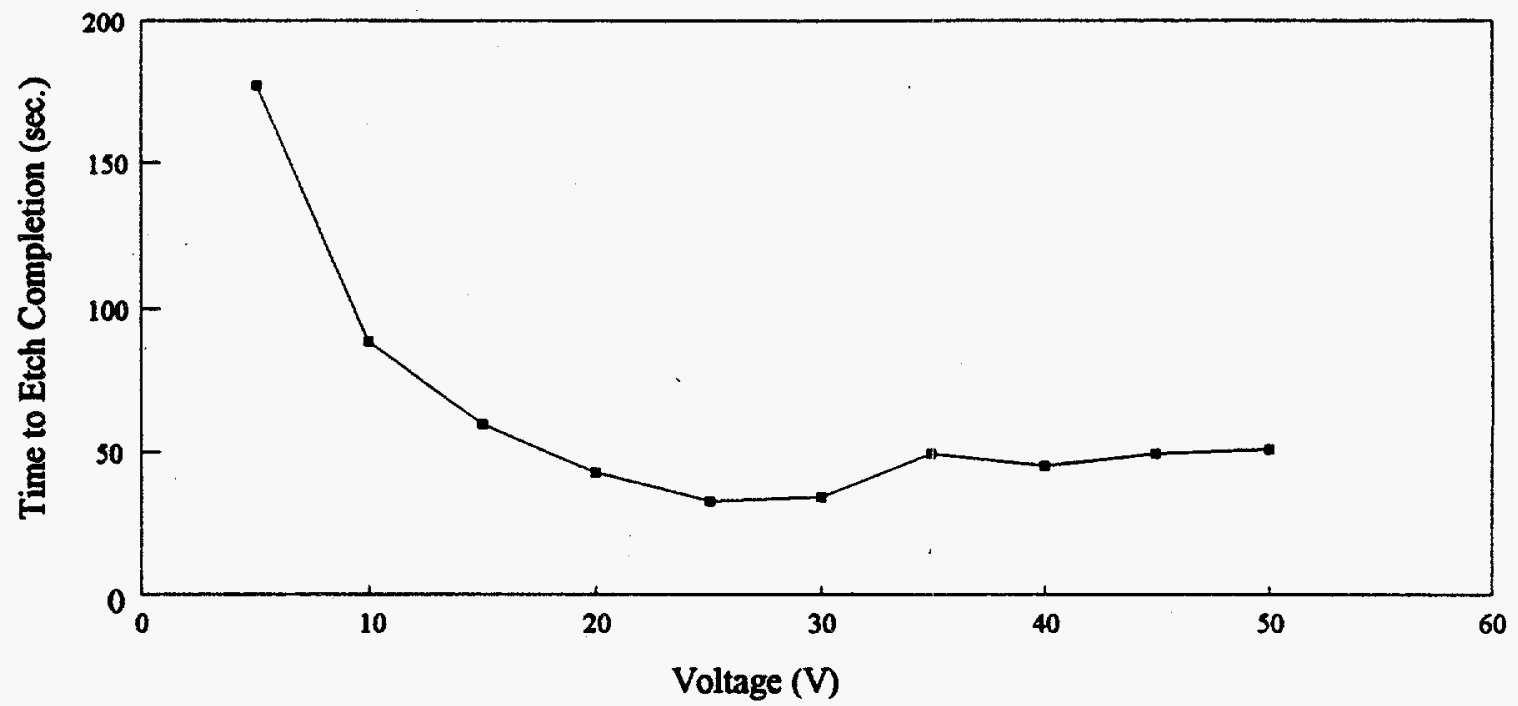

Figure 10. Plot of applied a.c. voltage vs. time to etch completion for a W wire immersed 2 $\mathrm{mm}$ into $1 \mathrm{M} \mathrm{KOH}$.

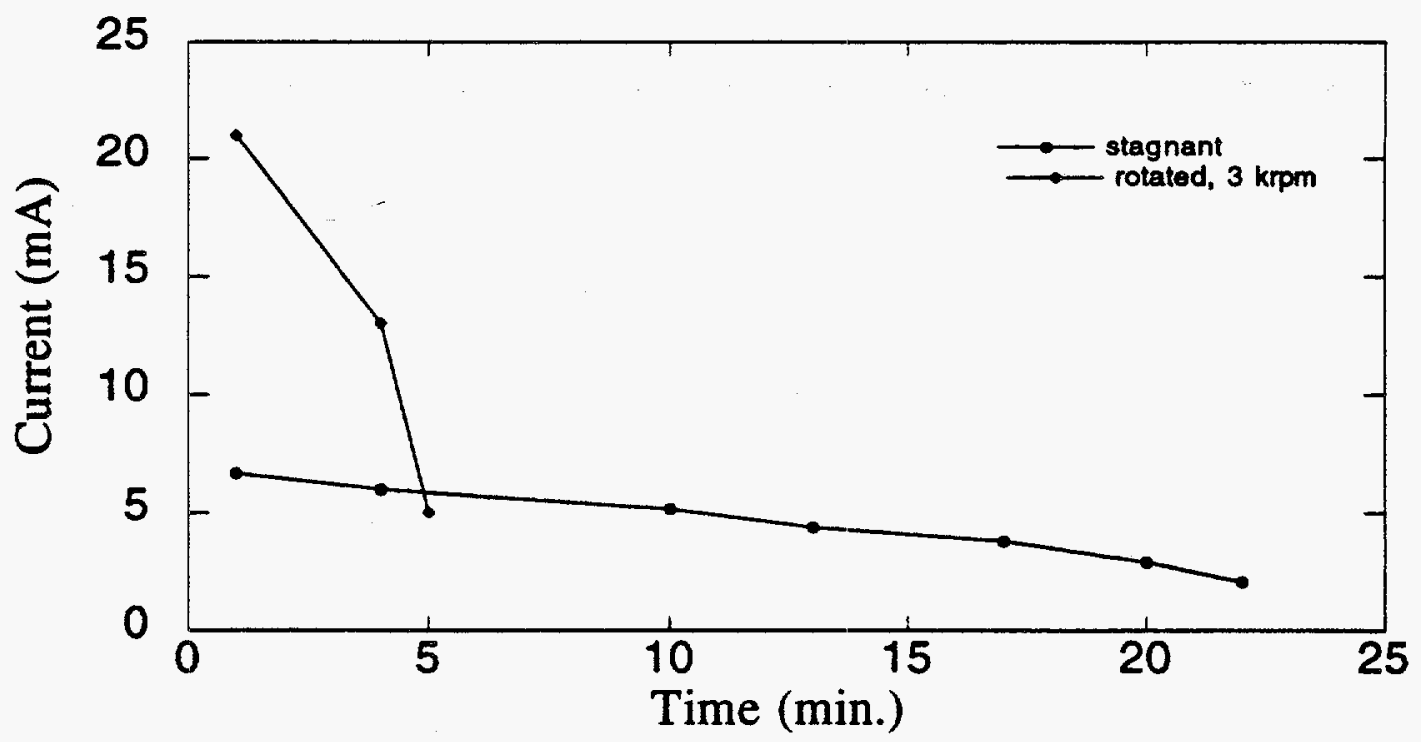

Figure 11. Comparison of current density vs. time for $\mathrm{W}$ wire etched in $1 \mathrm{M} \mathrm{NaOH}$ at $7 \mathrm{~V}$ d.c.: Rotated 3krpm vs. nonrotated wire. 
rotated, an increase in the supply of $\mathrm{OH}^{-}$ions to the metal electrode or an increase in the mass transport of the soluble $\mathrm{WO}_{4}^{-2}$ away from the electrode yielded a decrease in the etching time.

\section{Pt/Ir Etching Experiments}

Platinum wire ( 0.01 inch dia.) is a soft metal but alloying with the metals iridium and rhodium increase its hardness. Platinum/iridium is preferred over $W$ in most STM experiments because it is more chemically inert. Platinum/iridium etched in $\mathrm{CaCl}_{2}$ solution under a. c. voltage exhibited some of the etching characteristics of $\mathrm{W}$ in caustic solution. Above the breakdown voltage, oxygen evolution was observed at the electrode surface. The ferocity of this reaction increased with increasing voltage. At $25 \mathrm{~V}$ and above, sparking was witnessed. Similar to $\mathrm{W}$, sparking intensified on the $\mathrm{Pt} / \mathrm{Ir}$ wire with increasing voltage. Unlike $\mathrm{W}$, an insoluble black product was formed around the wire during the etching process. Analysis of these particle will be presented later in this report.

Under a.c. etching conditions, the amount of time to etch $\mathrm{Pt} / \mathrm{Ir}$ wire in a $\mathrm{CaCl}_{2}$ solution was found to be voltage dependent, as shown in Figure 12. The minimum etch time occurred at $25 \mathrm{~V}$, similar to $\mathrm{W}$. The etch time at this minimum is over $6 \mathrm{X}$ slower than for $\mathrm{W}$ wire etched in $\mathrm{NaOH}$. Further, this time increased with voltage above the minimum. Similar to the results shown for $W$, rotating the electrode led to a faster etching rate. Generally, the rotated rate was $2 \mathrm{X}$ faster than the rate under stagnant conditions. The current-voltage behavior was analyzed on an oscilloscope. The current wave was sinusoidal below $\approx 25 \mathrm{~V}$. At this voltage, many high intensity spikes appeared, particularly during the positive sweep. This change in current behavior corresponds to a commencement of sparking on the $\mathrm{Pt} / \mathrm{Ir}$ electrode at approximately $28 \mathrm{~V}$. These current spikes, associated with sparking, drove the reaction, reducing the etch time. Nonetheless, increasing the voltage above $28 \mathrm{~V}$ increased the total etch time as in the case of W in the high a.c. voltage regime.

The current-voltage behavior under d.c. voltage is shown in Figure 13. Between 8.1 and $40 \mathrm{~V}$, oxygen gas was evolved in an aggressive reaction with a corresponding increase in the current to a maximum of $15.7 \mathrm{~A} / \mathrm{cm}^{2}$. At $40 \mathrm{~V}$, gaseous evolution diminished and a corresponding decrease in current to $\approx 2.7 \mathrm{~A} / \mathrm{cm}^{2}$ was observed. Above $40 \mathrm{~V}$, current remained constant at this value. The wire began to show a purple glow above $65 \mathrm{~V}$, intensifying until sparking was observed near $90 \mathrm{~V}$. At $115 \mathrm{~V}$, small brown particles began to flake off the surface in spurts. Flakes increased in size with increasing voltage. Larger flakes burst from the surface accompanied by a popping sound. The time to etch $\mathrm{Pt} / \mathrm{Ir}$ under d. c. voltage conditions ranged from several tens of minutes to hours, thus making it impractical for use as STM or SVP tips. Also, SEM results of tips etched 


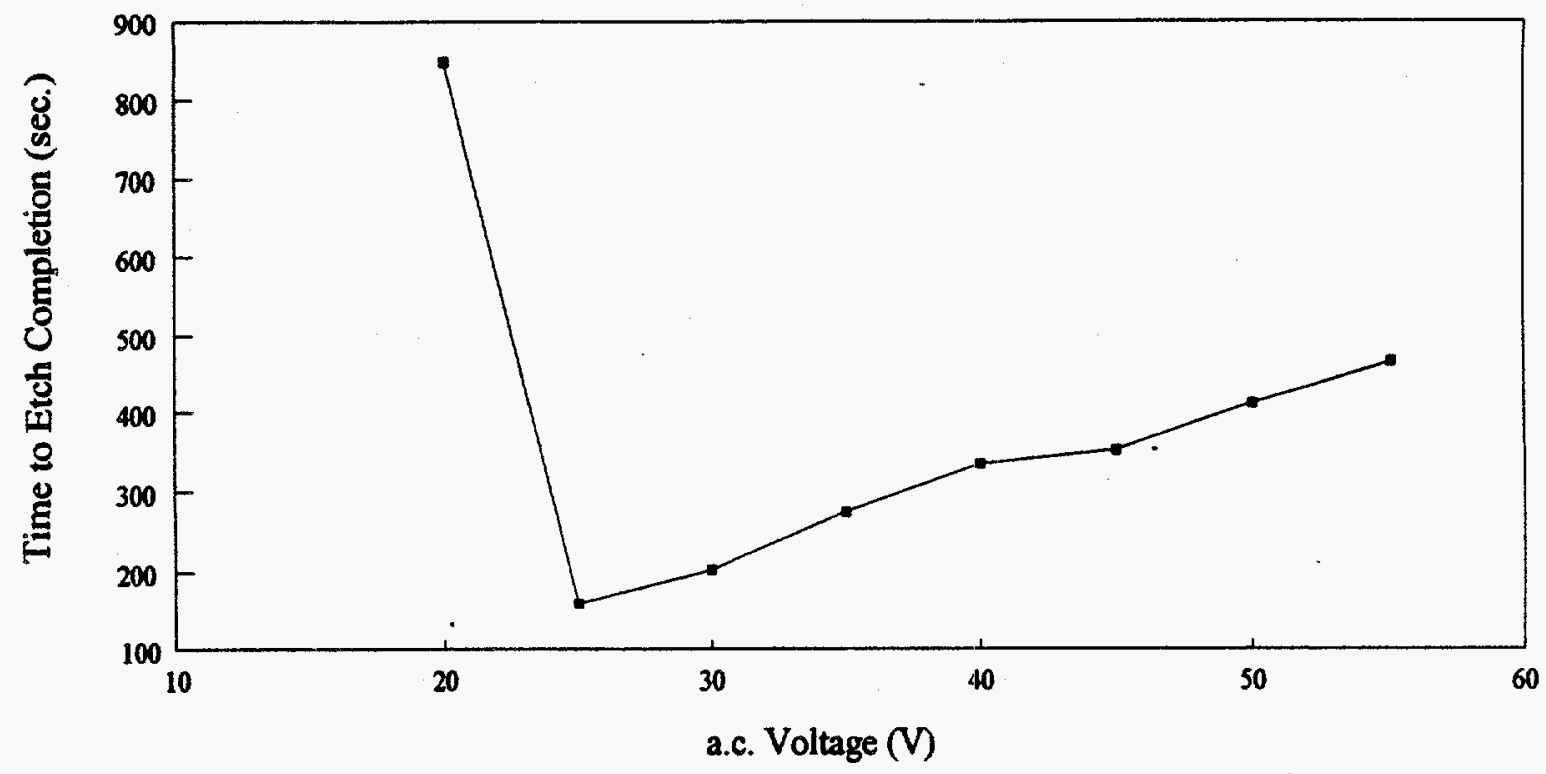

Figure 12. Plot of applied a.c. voltage vs. time to etch completion for a $\mathrm{Pt} / \mathrm{Ir}$ wire immersed $2 \mathrm{~mm}$ into $2: 1 \mathrm{H}_{2} \mathrm{O}$ : saturated $\mathrm{CaCl}_{2}$.

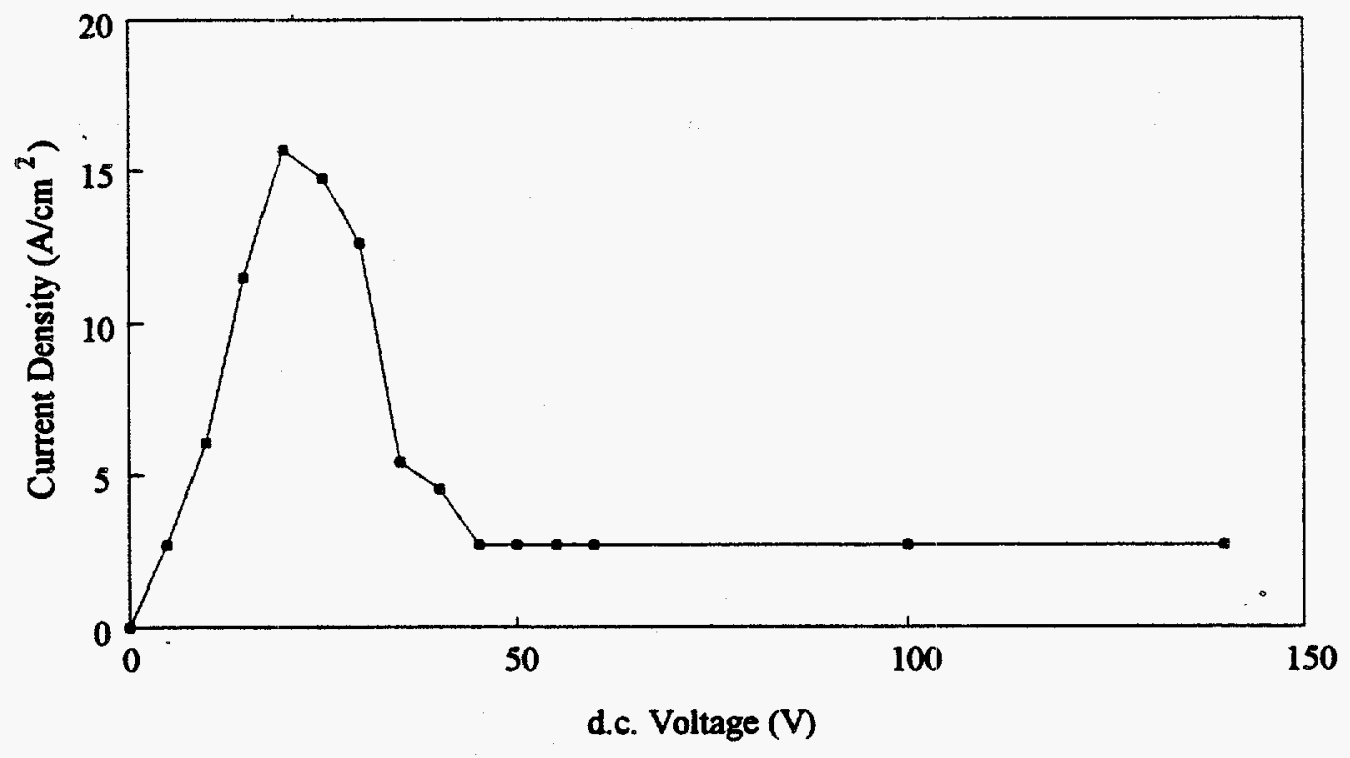

Figure 13. Current density vs. applied d.c. voltage for $\mathrm{Pt} / \mathrm{Ir}$ wire etched in $2: 1$ $\mathrm{H}_{2} \mathrm{O}$ : saturated $\mathrm{CaCl}_{2}$. 
at various voltages (not shown) indicate that these tips are very blunt and had low aspect ratios.

An insoluble black product was always observed during etching of $\mathrm{Pt} / \mathrm{Ir}$ at voltages above $20 \mathrm{~V}$ a.c. and $115 \mathrm{~V}$ d.c. This insoluble product was filtered and rinsed with deionized water several times and then analyzed using a TEM equipped with an energy dispersive analyzer for determination of the particle size and composition. An EDS spectrum of the product formed during an a. c. etch is shown in Figure 14. The elements associated with each peak are marked in the figure. Although a full compositional analysis has not been completed, it has been determined from the spectrum that the major substituents of this product are platinum and iridium, the original components in the wire. Further, TEM results indicated that the product formed during the etch process is submicron in dimension. In fact, results (not shown) indicate that these particles have nanometer dimensions (between $3-6 \mathrm{~nm}$ ). Research will continue in this area in order to determine the exact compositional ratio of the nanoparticles that are formed.

\section{Light Emission Studies}

The light emitted during sparking of $\mathrm{Pt} / \mathrm{Ir}$ in $\mathrm{CaCl}_{2}$ was monitored using a scanning monochromator. Spectra obtained during the sparking process at 100 and $150 \mathrm{~V}$ d.c. are shown in Figure $15 \mathrm{~A}$ and $15 \mathrm{~B}$, respectively. Each spectrum represents a summation of ten consecutive sweeps from 200 to $650 \mathrm{~nm}$. Each sweep took 0.5 seconds to complete. Broadening of the line intensities was due to continuous fluctuation of the sparking event. Individual line wavelengths were compared with known light emission wavelengths and their harmonics for all elements in the etching solution: $\mathrm{Pt}, \mathrm{Ir}, \mathrm{Ca}$, and $\mathrm{Cl}$ as well as the components in air: $\mathrm{H}, \mathrm{O}, \mathrm{N}$ and $\mathrm{C}$. Line assignments for the high intensity lines are marked in Figure 15A and 15B. Peak assignments on the spectrum taken at $100 \mathrm{~V}$ indicate that $\mathrm{Pt}$ and $\mathrm{Ca}$ are the strongest contributors to the sparking process. At a higher etching voltage of $150 \mathrm{~V}$, additional spectral lines emerged as shown in Figure 15B. This increase in voltage enables higher energy transitions to appear while still retaining all major lines observed in the $100 \mathrm{~V}$ spectrum. In the high voltage spectrum, all of the elements ( $\mathrm{Pt}, \mathrm{Ir}, \mathrm{Ca}$ and $\mathrm{Cl}$ ) associated with sparking are identified as peaks in the spectrum. It should be noted that ionization of $\mathrm{Pt}$ and $\mathrm{Ir}$ require several thousand $\mathrm{C}^{\circ}$ to emit light.

Light emission studies during sparking of a $\mathrm{W}$ wire in $\mathrm{NaOH}$ and $\mathrm{KOH}$ (not shown) have also been performed. In each case, the spectra consisted of numerous low intensity lines superimposed on a background of white light. Only a preliminary investigation of these studies has been executed. It was visually apparent that transitions of $\mathrm{Na}$ occurred during $\mathrm{W}$ etched in a $\mathrm{NaOH}$ solution because sparks of yellow/orange were observed. For $\mathrm{W}$ etched in $\mathrm{KOH}$, sparks of violet were observed. These colors are 


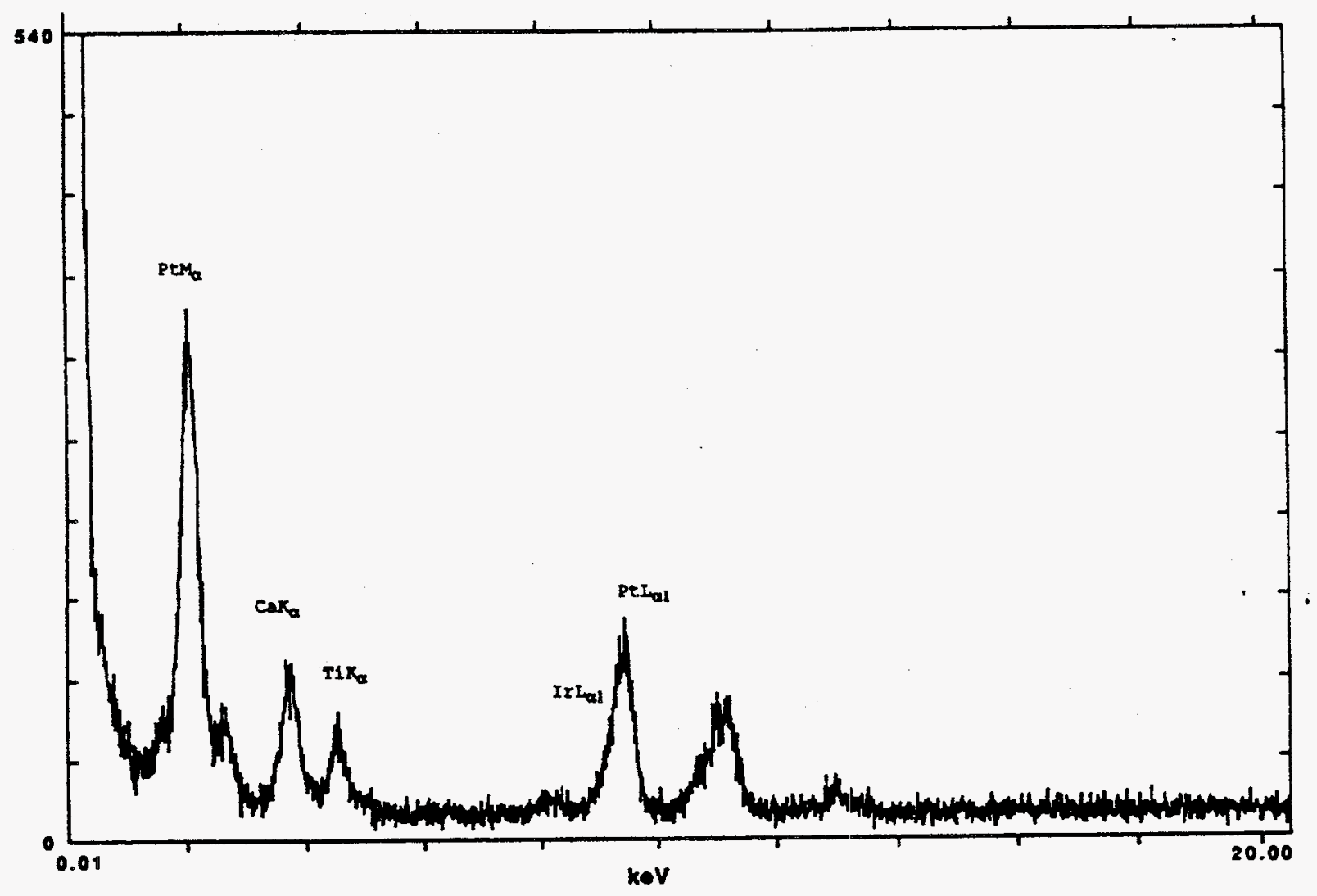

Figure 14. Energy dispersive spectrogram of particles formed during a $\mathrm{Pt} / \mathrm{tr}$ etch in $2: 1 \mathrm{H}_{2} \mathrm{O}$ : saturated $\mathrm{CaCl}_{2}$ solution. 

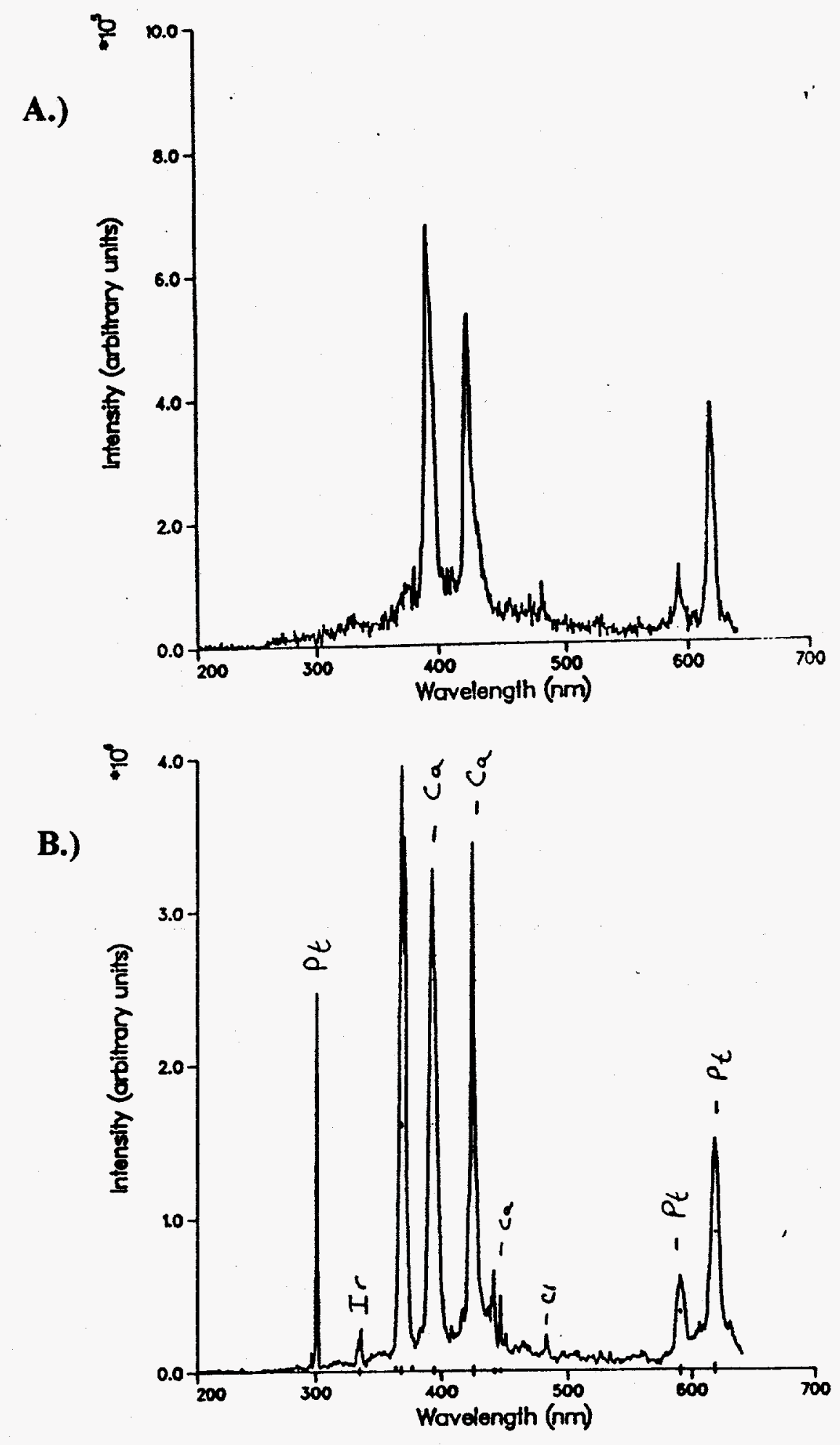

Figure 15. Light emission spectra of sparking during an etch of $\mathrm{Pt} / \mathrm{r}$ in 2:1 $\mathrm{H}_{2} \mathrm{O}: \mathrm{CaCl}_{2}$ at A.) $100 \mathrm{~V} \mathrm{d.c.} \mathrm{and} \mathrm{B.)} 150 \mathrm{~V}$ d.c.. 
indicative of the colors emitted during ionization of $\mathrm{Na}$ and $\mathrm{K}$ cations.

\section{The Etching Mechanism}

For $\mathrm{Pt} / \mathrm{Ir}$ and $\mathrm{W}$ etched at high voltages, two distinct events take place in conjunction with electrochemical processes: vigorous gas evolution and sparking. The evolved gas was observed to flow from the apex of the shaft in an upward stream to the meniscus at the solution/air interface as determined by frame by frame analysis of video footage of the etch. Once the gas reached the meniscus, it flowed radially outward from the wire and quickly dissipated. The ferocity of this reaction may produce enough energy to cause cavitation at the wire surface [6]. It has been shown that a violent collapse of bubbles at a metal interface can lead to intense temperatures near $5000 \mathrm{C}^{\circ}$ and light emission [19]. The action of these bubbles on the electrode may increase the rate of dissolution by continuously eroding the surface. In the case of $\mathrm{W}$ etching, this would increase the rate of electrochemical dissolution by continuously creating a new surface in which the surface oxide is chemically dissolved. In the case of $\mathrm{Pt} / \mathrm{Ir}$, this erosion mechanism may explain the production of $\mathrm{Pt} / \mathrm{Ir}$ nanoparticles which form during the etching process.

During sparking at high voltages, light from thermionic emissions was observed. As indicated above, transitions from the $\mathrm{Pt}$ and $\mathrm{Ir}$ etched in chloride solutions were observed as well as $\mathrm{W}$ in caustic solutions (not shown). For these metals to ionize, temperatures above $2000 \mathrm{C}^{\circ}$ are required. Thus localized sparking regions having temperatures in excess of the boiling points of $\mathrm{Pt}$, $\mathrm{Ir}$, and $\mathrm{W}$ are created. In a phenomenon similar to electrical discharge machining (EDM), the metal is ionized into a vapor at these localized regions. By solution convection, the vaporized metal is quickly removed from the high temperature zone to the surrounding solution, cooling and resolidifying in small particulates. This may also explain the formation of nanoparticles during the etch of $\mathrm{Pt} / \mathrm{Ir}$ in $\mathrm{Cl}^{-}$containing solutions.

To summarize, below $25 \mathrm{~V}$, where sparking initiated, the etching process was driven by cavitation from gas flow. In the intermediate voltage regime, a balance between cavitation and sparking was maintained until a point was reached where sparking consumes the entire tip. At high etching voltages above $=70 \mathrm{~V}$, intense sparking consumed the entire immersed shaft throughout the etching process, thereby, substantially overpowering the effects of cavitation.

\section{Micromachining}

High intensity sparking within a localized area at the apex of a tip may have applications in micromachining via a technique similar to electrical discharge machining 
(EDM). EDM entails the application of a high voltage between a sample and cutting wire which produces a large electric field [20]. This voltage heats the cathode, allowing for thermionic emission of electrons which flow to the anode, particularly the area of the anode directly adjacent to the cathode. Once the dielectric material, usually a kerosenebased electrolyte, has reached its breakdown potential, a channel for the thermally emitted electrons is created. Atoms on the sample surface, ionized by the incoming electrons, flow away from the cathode surface towards the negatively charged side of the dielectric. This process generates a large amount of heat which melts and then boils the metal of the anodic sample. The vaporous metal is removed from the surface by a magnetic field and dielectric flow.

A number of experiments have been carried out in order to judge the applicability of using sparking tips to perform micromachining. Pre-etched $\mathrm{Pt} / \mathrm{Ir}$ and $\mathrm{W}$ tips were placed in close proximity of one another. Each tip was immersed $2 \mathrm{~mm}$ into a $1 \mathrm{M} \mathrm{NaOH}$ solution. At a.c. voltages below $30 \mathrm{~V}$, sparking and etching was observed exclusively on the $\mathrm{W}$ tip. At $40 \mathrm{~V}$, activity was seen on the Pt/Ir electrode, dulling its initially shiny surface. At $50 \mathrm{~V}$, an immediate and intense burst of white light occurred. The result of this reaction is shown in Figure 16. As seen in the figure, shiny ball-shapes formed on the ends of both electrodes. It should be noted that after the burst of light, no metal remained in the solution, and the observed protrusions were formed at the air-solution interface. A compositional analysis of the protrusions is underway in an effort to determine if melting of the individual wires had occurred and an alloy of Pt-Ir-W had formed.

The process was expanded in order to determine if deformations in a metal foil in close proximity to a sparking tip could be performed. A pre-etched $\mathrm{W}$ tip was placed in directly above and perpendicular to the surface of a thin $W$ foil (not shown). At $30 \mathrm{~V}$ a.c. in $1 \mathrm{M} \mathrm{NaOH}$, sparking ensued which induced a hole approximately $0.5 \mathrm{~mm}$ in diameter in the $\mathrm{W}$ foil. This event happened immediately after applying the voltage. Note that the tip did not touch the surface of the foil at any time during the experiment. The fundamental parameter which determined whether a hole would form at $30 \mathrm{~V}$ was the gap separation between the tip and the foil at the start of the experiment. Experimental results indicate that this separation needed to be less than $0.5 \mathrm{~mm}$. At voltages less than $30 \mathrm{~V}$, the $\mathrm{W}$ tip etched, increasing the gap separation, thus making hole formation less likely.

In order to achieve accurate and reproducible micromachining using this technology, a number of parameters would have to be controlled. The sparking event would have to be localized and controlled in a well-defined microspark. Further, the tip would have to be continually stepped toward the machining surface with a high precision positioner. Lastly, tip sparking must be localized to the tip apex to retain a point source for machining. Further research is needed in this area. 


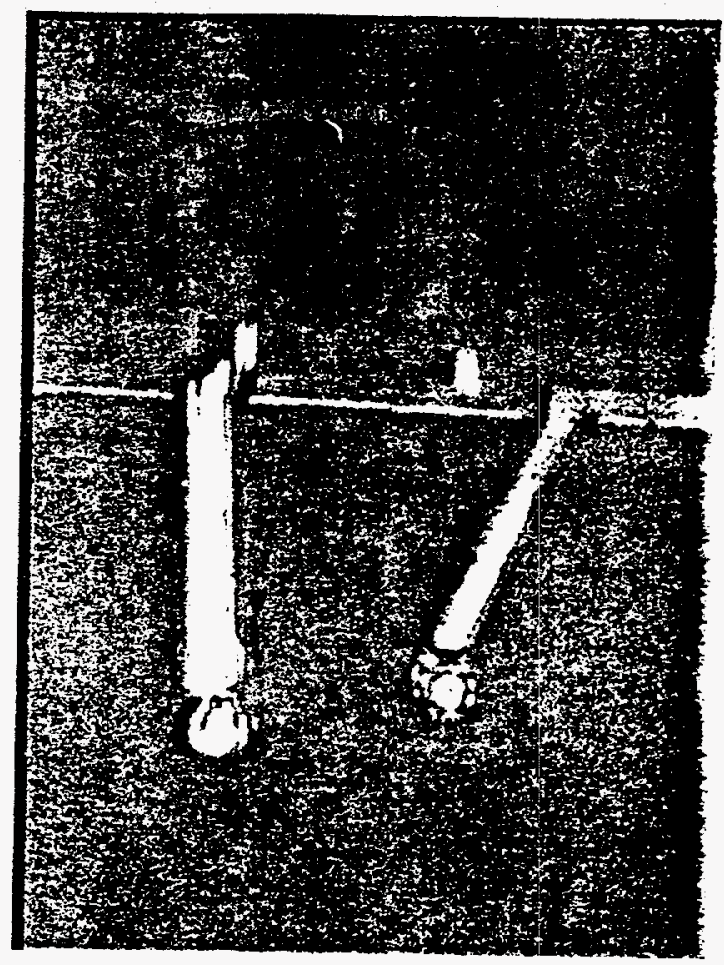

Figure 16. Photograph of $\mathrm{W}$ and $\mathrm{Pt} / \mathrm{Ir}$ wires after etching at $50 \mathrm{~V}$ a.c. in $\mathrm{IM}$ $\mathrm{NaOH}$. The melted balls were formed at the solution-air interface after sparking. 


\section{CONCLUSIONS}

An investigation to determine the mechanisms by which $\mathrm{Pt} / \mathrm{r}$ and $\mathrm{W}$ are electrochemically etched was presented. The rate of chemical dissolution of a W rod was found to be dependent on the $\mathrm{OH}^{\circ}$ concentration. The height of the meniscus and the resulting aspect ratio of etched tips were found to be directly dependent on applied voltage. Floating a nonpolar phase on top of the etching solution was also shown to alter the meniscus, creating higher aspect ratio $\mathrm{Pt} / \mathrm{Ir}$ tips. A minimum in the total etch time versus applied voltage was found to be $25 \mathrm{~V}$ for both wires. This corresponds with the beginning of sparking on the wires. At voltages above $25 \mathrm{~V}$, intense sparking on $\mathrm{W}$ and $\mathrm{Pt} / \mathrm{Ir}$ was observed. This increase in sparking led to an increase in total etch time. Two mechanisms were proposed to explain the etching process above the breakdown voltage: cavitation and sparking. Cavitation caused general erosion of the electrode due to high pressure bubbles bombarding the surface and sparking caused melting and vaporization of the surface due to intense heat generated during the spark. Black particles formed during both a.c. and d.c. etching of $\mathrm{Pt} / \mathrm{Ir}$ were evaluated using transmission electron microscopy with electron dispersive spectroscopy. Using these methods, it was determined that the particles were in the $3-6 \mathrm{~nm}$ range and consisted of mainly $\mathrm{Pt}$ and Ir as the major constituents of the product. The applicability of using sparking tips to micromachine was addressed. It was found that small holes could be formed in a metal foil under a sparking tip under suitable conditions. Lastly, light emission spectra of $\mathrm{Pt} / \mathrm{Ir}$ during an etching event indicated that $\mathrm{Pt}, \mathrm{Ir}, \mathrm{Ca}$, and $\mathrm{Cl}$ were ionized during the etch of $\mathrm{Pt} / \mathrm{Ir}$ in a $\mathrm{CaCl}_{2}$ solution.

\section{ACKNOWLEDGEMENTS}

One of us (V.S.) gratefully acknowledges support from the Department of Energy's Office of Science Education and Technical Information, Office of Energy Research, as a science and Engineering Research Semester (SERS) student. We would like to thank J. Kiersted for his assistance and advice in using the monochromator and R. Sabatini for training and use of the SEM and TEM. The work by C.M.V and H.S.I. was supported by the U.S. Department of Energy, Office of Basic Energy Science, Division of Materials Science under Contract NO. DE-AC02-76CH00016. 


\section{REFERENCES}

1.) E. W. Müller and T. T. Tsong in Field Ion Microscopy: Principles and Applications, American Elsevier, New York (1969).

2.) W. J. Tegart, The Electrolytic and Chemical Polishing of Metals, Pergamon Press, Oxford, 1959.

3.) P. A. Jacquet, Metallurgical Review, 1, 157 (1961).

4.) I. S. Brammar and M. A. P. Dewey, Specimen Preparation for Electron Metallography, American Elsevier, New York (1966).

5.) P.K. Hansma, V. B. Elings, O. Marti, C. E. Bracker, Science 242, 209 (1988).

6.) M. Fotino, Rev. Sci. Instrum. 64 (1), 159 (1993).

7.) I. H. Musselman, P. E. Russell, J. Vac. Sci. Technol. A 8 (4), 3558 (1990).

8.) B. Zhang and E. Wang, Electrochimica Acta 39 (1), 103 (1994).

9.) J. P. Ibe, P. P. Bey, Jr., S. L. Brandow, R. A. Brizzolara, N. A. Burnham, D. P. DiLella, K. P. Lee, C. R. K. Marrian and R. J. Colton, J. Vac. Sci. Technol. A 8 (4), 3570 (1990).

10.) D. K. Biegelsen, F. A. Ponce, and J. C. Tramontana, Appl. Phys. Lett. 54, 1223 (1989).

11.) H. Neddermeyer and M. Drechsler, J. Microsc. 152, 459 (1988).

12.) V. T. Binh, J. Microsc. 152, 355 (1988).

13.) G. W. Stupian and M. S. Leing, Rev. Sci. Instrum. 60, 181 (1989).

14.) G. Binning, H. Rohrer, Ch. Gerber, and E. Weibel, Phys. Rev. Lett. 49, 57 (1982).

15.) W. J. Moore, Physical Chemistry, Longmans, London (1957).

16.) P. I. Ortiz, M. L. Teijelo, and M. C. Giordano, J. Electroanal. Chem. 243, 379 (1988). 
17.) G. S. Kelsey, J. Electrochem. Soc. 124 (6), 814 (1977).

18.) J. W. Johnson, and C. L. Wu, J. Electrochem. Soc. 118 (12), 1909 (1971).

19.) P. Yam, Sci. Amer., 24 (1993).

20.) P. F. Thomson, Mat. Sci. Tech. 5, 1153 (1989). 


\section{FIGURE CAPTIONS}

Figure 1. A sketch of the apparatus used to etch $\mathrm{W}$ and $\mathrm{Pt} / \mathrm{Ir}$ wires.

Figure 2. Diagram of experimental cell used to study voltammetric behavior of $W$ in caustic solutions.

Figure 3. Model of tip formation during an electrochemical etch.

Figure 4. Model of meniscus shape at the air-metal interface before, during and after an electrochemical etch.

Figure 5. Model of meniscus shape as a function of shaft diameter at the air-metal interface during an electrochemical etch.

Figure 6. SEM micrographs of $\mathrm{W}$ etched at in $1 \mathrm{M} \mathrm{NaOH}$ at A.) $10 \mathrm{~V}$ a.c. B.) $30 \mathrm{~V}$ a.c. and $\mathrm{C}$.) $50 \mathrm{~V}$ a.c.

Figure 7. SEM micrographs of $\mathrm{Pt} / \mathrm{Ir}$ etched in $2: 1 \mathrm{H}_{2} \mathrm{O}: \mathrm{CaCl}_{2}$ at $20 \mathrm{~V}$ a.c. A.) without a nonpolar overlayer and $\mathrm{B}$.) with a nonpolar overlayer of oil on top of the solution.

Figure 8. A current-voltage plot of $\mathrm{W}$ rod in $0.0125 \mathrm{M} \mathrm{NaOH}$ with a total ion activity of $1 \mathrm{M}$ with addition of $\mathrm{Na}_{2} \mathrm{SO}_{4}$. Scan rate, $0.1 \mathrm{~V} / \mathrm{sec}$.

Figure 9. A current-voltage plot of $\mathrm{W}$ rod in $1 \mathrm{M} \mathrm{NaOH}$. Scan rate, $0.1 \mathrm{~V} / \mathrm{sec}$.

Figure 10. Plot of applied a.c. voltage vs. time to etch completion for a $W$ wire immersed $2 \mathrm{~mm}$ into $1 \mathrm{M} \mathrm{KOH}$.

Figure 11. Comparison of current density vs. time for $\mathrm{W}$ wire etched in $1 \mathrm{M} \mathrm{NaOH}$ at $7 \mathrm{~V}$ d.c.: Rotated $3 \mathrm{krpm}$ vs. nonrotated wire.

Figure 12. Plot of applied a.c. voltage vs. time to etch completion for a $\mathrm{Pt} / \mathrm{Ir}$ wire immersed $2 \mathrm{~mm}$ in $2: 1 \mathrm{H}_{2} \mathrm{O}$ : saturated $\mathrm{CaCl}_{2}$.

Figure 13. Current density vs. applied d.c. voltage for $\mathrm{Pt} / \mathrm{Ir}$ wire in $2: 1 \mathrm{H}_{2} \mathrm{O}$ : saturated $\mathrm{CaCl}_{2}$. 
Figure 14. Energy dispersive spectrogram of particles formed during a $\mathrm{Pt} / \mathrm{Ir}$ etch in $2: 1$ $\mathrm{H}_{2} \mathrm{O}$ : saturated $\mathrm{CaCl}_{2}$ solution .

Figure 15. Light emission spectra of sparking during an etch of $\mathrm{Pt} / \mathrm{Ir}$ in $2: 1 \mathrm{H}_{2} \mathrm{O}: \mathrm{CaCl}_{2}$ at A.) $100 \mathrm{~V}$ d.c. and B.) $150 \mathrm{~V} \mathrm{d.c..}$

Figure 16. Photograph of $\mathrm{W}$ and $\mathrm{Pt} / \mathrm{Ir}$ wires after etching at $50 \mathrm{~V}$ a.c. in $1 \mathrm{M} \mathrm{NaOH}$. The melted balls were formed at the solution-air interface after sparking. 